\title{
Large-scale atmospheric circulation patterns during polar low events over the Nordic seas
}

\author{
A.-M. Blechschmidt, ${ }^{1}$ S. Bakan, ${ }^{2}$ and H. Graß1, ${ }^{1,2}$ \\ Received 29 July 2008; revised 22 December 2008; accepted 15 January 2009; published 27 March 2009.
}

[1] The large-scale atmospheric circulation during polar low events over the Nordic seas (the North Atlantic between Greenland and Novaya Zemlya) is investigated on the basis of a recently compiled data set that was derived purely from satellite observations. A classification system is applied that divides the polar lows into four types (western polar lows, eastern polar lows, Greenland lee polar lows, and storm track polar lows). Type-specific large-scale atmospheric circulation patterns are identified from National Centers for Environmental Prediction reanalysis data. These are distinct in sea level pressure, upper level geopotential height, and the difference between the skin temperature of the ocean and upper level temperature. Eastern polar lows are found to be associated with a strong blocking situation caused by anomalously high pressure over Iceland and a synoptic-scale low-pressure anomaly over the Barents Sea. A weaker blocking situation with an anomalous ridge over Greenland reaching into the Irminger Sea and a low-pressure anomaly over the Norwegian Sea favors the development of western polar lows. Typical values for polar low genesis are a geopotential height of 5030 geopotential meters at $500 \mathrm{hPa}$ and a difference of $48 \mathrm{~K}$ between the skin temperature of the ocean and the temperature at $500 \mathrm{hPa}$. The locations of upper level low-pressure anomalies relative to the locations of the related anomalies at the sea level show that western and eastern polar lows form, on average, in a much less baroclinic large-scale environment than Greenland lee and storm track polar lows.

Citation: Blechschmidt, A.-M., S. Bakan, and H. Graß1 (2009), Large-scale atmospheric circulation patterns during polar low events over the Nordic seas, J. Geophys. Res., 114, D06115, doi:10.1029/2008JD010865.

\section{Introduction}

[2] Polar lows are intense maritime mesocyclones at high latitudes. They often form when cold air flows over relatively warm water. The Nordic seas region is prone to polar low development because strong horizontal SST gradients occur in the regions adjacent to the ice edge. Several forcing mechanisms for the development of polar lows have been discussed in literature. One point of view is that polar lows are essentially baroclinic disturbances [e.g., Mansfield, 1974; Reed and Duncan, 1987] of short wavelength, i.e., the same type of systems as the well-known extratropical cyclones [Harrold and Browning, 1969]. In contrast to this, others suggested that a polar low is basically a thermal instability phenomenon much akin to a small tropical cyclone [e.g., Rasmussen, 1979; Emanuel and Rotunno, 1989]. Barotropic instability has also been regarded as a possible forcing mechanism [e.g., Reed, 1979; Rasmussen, 1983; Sardie and Warner, 1985]. The wealth of underlying instability mechanisms resulted in the idea of a "spectrum" of polar lows ranging from purely baroclinic to purely convective systems. However, the structure of most polar

\footnotetext{
${ }^{1}$ Meteorological Institute, University of Hamburg, Hamburg, Germany.

${ }^{2}$ Max Planck Institute for Meteorology, Hamburg, Germany.
}

Copyright 2009 by the American Geophysical Union. 0148-0227/09/2008JD010865\$09.00 lows is a hybrid between these extremes [Bracegirdle and Gray, 2008].

[3] Several methods for classifying polar lows have been proposed to represent the different types that constitute the polar low spectrum. For example, Rasmussen [1983] distinguished between spiral-shaped and comma-shaped polar lows referring to the first type as "real" or "true" polar lows. Businger and Reed [1989] differentiated three elementary types of polar low developments on the basis of associated synoptic patterns. These types were thought to be pronounced in the degree and distribution of baroclinicity, static stability and surface fluxes of latent and sensible heat. Rasmussen and Turner [2003] tried to improve this classification by developing a scheme partly on the basis of synoptic patterns and partly on the basic mechanisms for polar low formation. It consisted of seven different polar low types occurring over the Norwegian Sea (orographic polar lows, trough systems, cold lows, boundary layer fronts, comma clouds, reverse shear systems and the baroclinic wave-forward shear type).

[4] Because of the small-scale and short lifetimes of polar lows they are not adequately represented in coarse grid numerical models. Condron et al. [2006] showed that a large portion of polar mesocyclones is not present in the ERA-40 reanalysis. However, reanalysis data have proven as a valuable tool for investigating the large-scale conditions in which these systems form. For example, Businger [1985] 
computed anomaly charts of surface pressure and $500 \mathrm{hPa}$ height fields by averaging National Meteorological Center (NMC) data for 52 polar lows near Norway in the period from 1970 to 1982 . The study revealed the presence of significant negative anomalies of temperature and height fields at the $500 \mathrm{hPa}$ level over the Norwegian and Barents seas, indicating strong positive vorticity and very low static stability at the days when mature polar lows were present [Businger, 1985]. Ese et al. [1988] supplemented this work by applying a mostly similar analysis to the polar lows first observed west of $5^{\circ} \mathrm{E}$ longitude and to those first observed east of $5^{\circ} \mathrm{E}$. They found distinct upper and lower level patterns for the investigated regions.

[5] Instead of analyzing the large-scale environment of observed polar low cases, some studies investigated largescale situations that are known to be favorable for polar low development. Claud et al. [2007] used temperature at $500 \mathrm{hPa}$, geopotential height at $500 \mathrm{hPa}$, wind at $925 \mathrm{hPa}$, SST and the difference between the SST and the temperature at $500 \mathrm{hPa}$ from reanalysis data between 1979 and 2001 to evaluate the relations between several teleconnection patterns and polar lows over the North Atlantic. They found that the NAO has a strong impact on all these variables, and hence on the likelihood of polar low formation. Kolstad et al. [2008] constructed anomaly charts of sea level pressure and geopotential height at $500 \mathrm{hPa}$ during wintertime marine cold air outbreaks (MCAOs) for three regions over the North Atlantic using reanalysis data from 1958 to 2007. The surface pressure composites showed an anomalous low over Iceland for MCAOs over the Labrador and the Irminger seas, a dipole consisting of an anomalous low over the Baltic region and an anomalous high near southeast Greenland for MCAOs over the Greenland-Iceland-Norwegian (GIN) seas and another dipole with centers of action near Nowaya Zemlya and Iceland for MCAOs over the Barents Sea.

[6] Besides the studies described above, results from numerical models that are able to resolve polar lows contributed to our understanding of the atmospheric conditions in which these systems form [e.g., Grønås and Kvamstø, 1995; Bracegirdle and Gray, 2008]. Zahn et al. [2008] found recently that a limited area model is capable of simulating polar lows if the large-scale circulation, as given by the National Centers for Environmental Prediction (NCEP) reanalysis, is enforced on the simulation using the spectral nudging technique. This shows that the largescale circulation can play a crucial role for polar low genesis.

[7] To our knowledge no study of the large-scale circulation, comparable to that of Businger [1985] exists, that bases directly on observed cases of polar lows for the Nordic seas. An appropriate polar low data set as a basis for such a study was recently published by Blechschmidt [2008]. This 2-year data set documents the evolution and pathways of 90 polar low events over the Nordic seas detected purely by combined use of thermal infrared satellite imagery and satellite derived wind speeds. In the present paper the large-scale circulation associated with these polar low cases is investigated. The methodology is comparable to that of Businger [1985]. However, since the geographical area of the present study is larger, a simple classification system is applied to account for regionally varying characteristics of polar lows and different forcing mechanisms. Type-specific, large-scale atmospheric circulation patterns are identified from NCEP reanalysis data. This is done by applying a composite analysis to the polar low types. It will be shown that the identified patterns are distinct in sea level pressure, upper level geopotential height and the difference between the skin temperature of the ocean and upper level temperature.

\section{Data}

[8] In the following, the main features of the polar low data set and the coarse grid reanalysis data are described.

\subsection{Polar Lows}

[9] Blechschmidt [2008] presented a 2-year climatology of polar low events over the ice-free parts of the Nordic seas (i.e., the North Atlantic between $60^{\circ}$ and $80^{\circ}$ latitude and between Greenland and Novaya Zemlya) from the combined use of thermal infrared satellite imagery and SSM/I derived wind speeds for the years 2004 and 2005. Polar lows were defined as cyclonic systems with diameters not bigger than $1000 \mathrm{~km}$ and wind speeds of at least $15 \mathrm{~m} / \mathrm{s}$ in the satellite climatology Hamburg Ocean Atmosphere Parameters and Fluxes from Satellite (HOAPS) data [Andersson et $a l ., 2007]$. As such, the data set is the first comprehensive one for the Nordic seas which is consistent with the widely used definition of the term "polar low" by Rasmussen and Turner [2003]. The mature stages of the polar lows were identified by eye inspection at the times when the polar lows appeared fully developed on the thermal infrared satellite images. The data set consists of 90 polar low events which mostly appeared during the winter months. Polar low activity was higher in the year 2004 than in 2005, mainly due to more frequent outbreaks of cold air into the study area in 2004. Most of the polar lows lived only for about $15 \mathrm{~h}$ and the maximum lifetime was 3 days. The majority of polar lows $(67 \%)$ originated over the Norwegian Sea between Iceland and the northeastern Norway. A secondary maximum in polar low activity was identified over the Barents Sea (22\% developed here). Fewer polar lows (11\%) formed between southern Greenland and Iceland. Maximum wind speeds of $18 \mathrm{~m} / \mathrm{s}$, maximum precipitation rates of $2.5 \mathrm{~mm} / \mathrm{h}$, maximum latent heat fluxes of $250 \mathrm{~W} / \mathrm{m}^{2}$, minimum cloud top temperatures of $215 \mathrm{~K}$ and minimum cloud top pressures of $300 \mathrm{hPa}$ were most frequently observed during the polar low events. The findings showed that polar lows over the Nordic seas are short-lived and small sized but very intense phenomena.

\subsection{NCEP Reanalysis}

[10] For the analysis of the large-scale situation during polar low events, four times daily NCEP-DOE AMIP-II Reanalysis (R-2) data for the years 2004 and 2005 with a spatial resolution of $2.5^{\circ}$ on 17 pressure levels was provided by the NOAA/OAR/ESRL PSD through their web site at http:/www.cdc.noaa.gov/. This is an updated global analysis series, which fixes processing errors in the NCEP-NCAR Reanalysis (R-1) [Kanamitsu et al., 2002]. We make use of the R-2 data set to rule out these errors in the composite analysis. 
[11] Since isentropic potential vorticity is not available in the R-2 data set, we obtained this parameter from the R-1 data set provided by the CISL Research Data Archive (http://dss.uc ar.edu/), where it is available on 11 isentropic levels.

\section{Classification}

[12] The geographical distribution of polar lows presented by Blechschmidt [2008] suggests to divide the polar lows into those developing over the Barents Sea (eastern polar lows), polar lows developing over the GIN Sea (western polar lows) and polar lows that develop in the lee of Greenland between South Greenland and Iceland (Greenland lee polar lows). The $15^{\circ} \mathrm{E}$ meridian is used as the longitudinal separator between eastern and western polar lows. This separator is much more appropriate than using the $5^{\circ} \mathrm{E}$ separator of Ese et al. [1988] because it better distinguishes between the major genesis regions of the polar low events near Norway identified in the previous study by Blechschmidt [2008]. The three classes described above are broadly the same as those investigated by Kolstad et al. [2008]. However, we differentiate these from a fourth class that consists of polar lows which develop when a synopticscale cyclone appearing in the reanalysis sea level pressure field moves along the major storm track (called "storm track polar lows" in the following). According to Whittaker and Horn [1984] the major storm track starts east of South Greenland and propagates further northeastward into the Norwegian and Barents seas. Storm track polar lows can principally form in the same geographic region as western and eastern polar lows. This polar low type is comparable to the "trough systems" defined by Rasmussen and Turner [2003] which are characterized by high values of low-level vorticity on the western flank of the synoptic-scale lows.

\section{Composite Analysis}

[13] Mean fields of sea level pressure, geopotential height at $500 \mathrm{hPa}\left(\mathrm{GPH}_{500}\right)$ and skin temperature minus temperature at the $500 \mathrm{hPa}$ level $\left(\mathrm{SKT} \mathrm{T}_{500}\right)$ are calculated independently for each polar low class described above. Mean fields of temperature at the $500 \mathrm{hPa}$ level $\left(\mathrm{T}_{500}\right)$ have also been computed for consistency and used in the analysis but will not be displayed. These parameters have been regarded as key factors for polar low development in previous studies [e.g., Noer and Ovhed, 2003; Claud et al., 2007; Zahn and von Storch, 2008].

[14] The mean fields are computed for those time steps of the NCEP reanalysis that are the last available before the mature stages (termed "key date" in the following) of the polar lows and for time steps before and after the key date. Since the polar lows do not live longer than 3 days, it is expected that a time window of $84 \mathrm{~h}$ centered on the key date represents the life cycle of a polar low. Consequently, the time steps before the key date correspond to the developing phase while the time steps after the key date are defined as the decaying phase of the cyclones. The analysis is performed every $6 \mathrm{~h}$. The resulting mean fields are termed "polar low mean fields" in the following.

[15] Additionally, mean fields over the analysis period 2004 and 2005 from which the key dates are excluded (termed "2-year complementary mean fields" in the following) of sea level pressure, $\mathrm{GPH}_{500}, \mathrm{~T}_{500}$ and SKT-T 500 are calculated for each polar low type. In analogy to the polar low mean fields, the 2-year complementary mean fields are also calculated excluding the time steps relative to the key dates. Anomaly maps are then produced by subtracting the 2-year complementary mean fields from the polar low mean fields. A Mann-Whitney test [Mann and Whitney, 1947] is applied to evaluate if the polar low mean fields differ significantly from the 2-year complementary mean fields. Note that 2-year complementary mean fields were used instead of mean fields over the whole period from 2004 to 2005 (2-year mean fields) to ensure independency of the underlying time series to which the significance test is applied. However, since the 2-year complementary mean fields do not differ much from the 2-year mean fields, only the latter will be discussed in the following.

\section{Analysis of Polar Low Events}

[16] In this section the results of the composite analysis for the four polar low types are described. The group of western polar lows consists of 42 cases, the group of eastern polar lows of 15, the group of Greenland lee polar lows of 10 and the group of storm track polar lows of 23 cases. To complete the analysis, typical values of $\mathrm{GPH}_{500}, \mathrm{~T}_{500}$, SKT$\mathrm{T}_{500}$ and isentropic potential vorticity at the $315 \mathrm{~K}$ potential temperature level $\left(\mathrm{IPV}_{315}\right)$ connected with polar low events are given in section 5.3 . In more than $80 \%$ of the 90 polar low events on which the present study bases, surface pressure lows and $\mathrm{GPH}_{500}$ lows or troughs as well as areas of high SKT-T $_{500}$ are situated over the genesis area of the polar lows. Hence, most of the observed polar low cases by Blechschmidt [2008] are linked to these disturbances. However, the present study focuses on the large-scale conditions occurring "on average" for the investigated polar low types. Therefore, the terms mean low (ML), mean trough (MT), and mean flow (MF) are used in the following to point out that mean patterns rather than instantaneous atmospheric fields are described.

\subsection{The 2-Year Mean Fields}

[17] Figure 1 shows the mean field of NCEP reanalysis sea level pressure, $\mathrm{GPH}_{500}$ and $\mathrm{SKT} \mathrm{T}_{500}$ for the years 2004 and 2005. A ML over Iceland and a second ML close to the Norwegian coast are visible. Although derived over a different time period and over the whole months of a year, this mean field is in agreement with the climatological surface map for the winter season of the years 1946 to 1979 calculated by Ese et al. [1988].

[18] An upper level cold MT to the west of Greenland is present in the 2-year mean fields of $\mathrm{GPH}_{500}$ (not clearly shown by the geographical area in Figure 1b). This parameter increases toward lower latitudes and is associated with the typical upper air flow of the circumpolar vortex. A maximum of SKT-T 500 lies over the Norwegian Sea. Strong gradients of SKT-T 500 occur adjacent to the ice edge.

\subsection{Polar Low Mean Fields and Anomaly Maps}

[19] In this section the polar low mean fields and anomaly maps of western, eastern, Greenland lee and storm track 
(a)
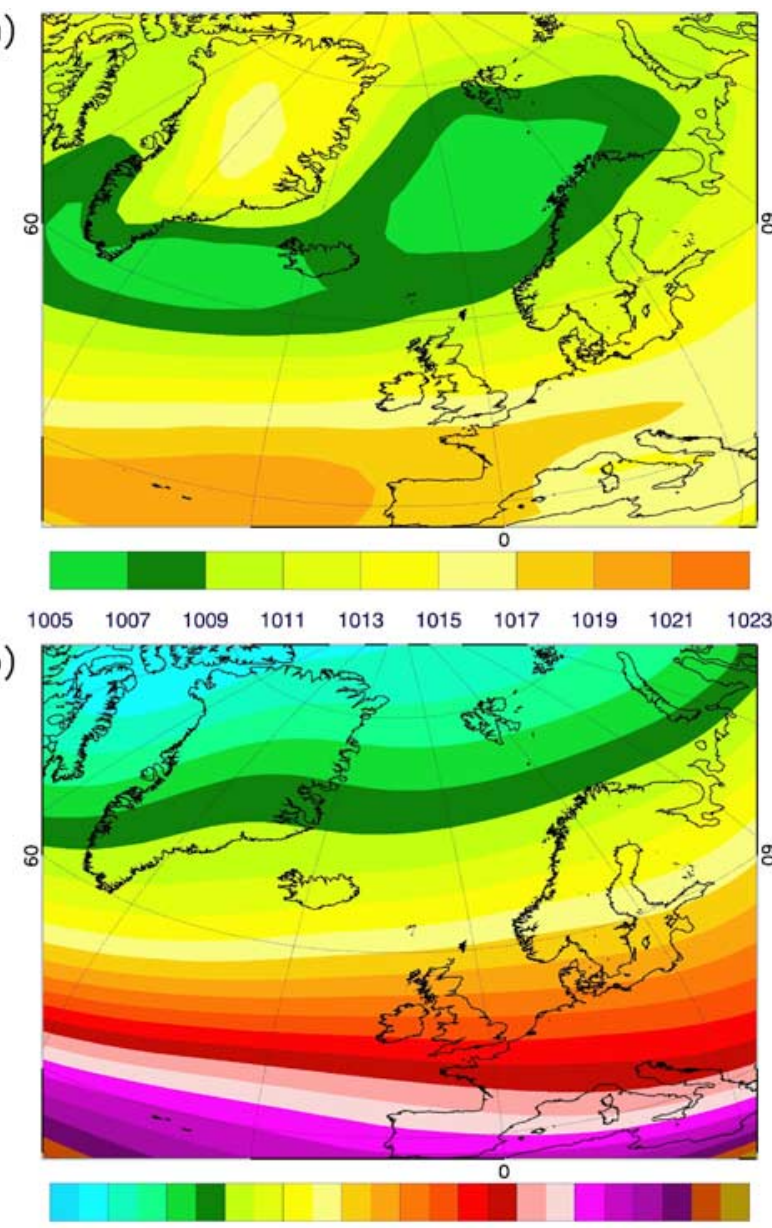

5180524053005360542054805540560056605720578058405900

(c)

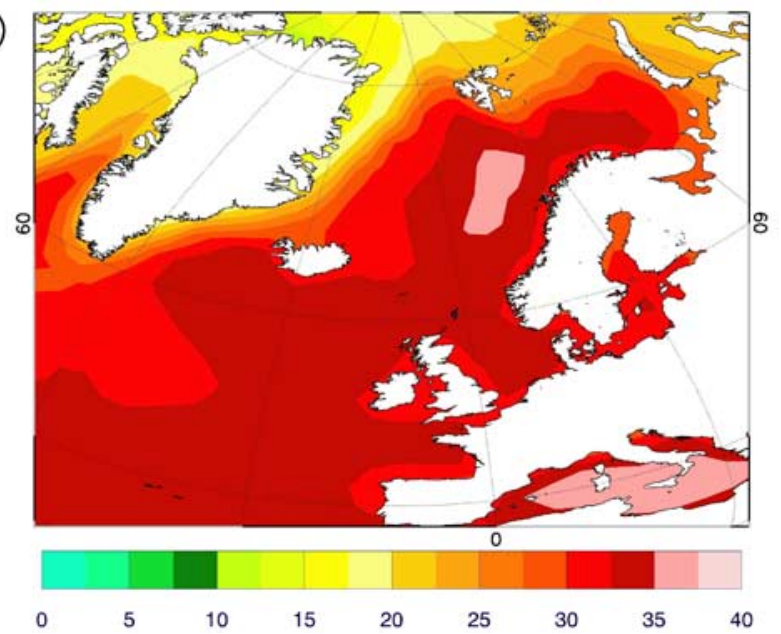

Figure 1. Mean of (a) sea level pressure [hPa], (b) $\mathrm{GPH}_{500}$ (gpm) and (c) SKT-T $500[\mathrm{~K}]$ for the years 2004 and 2005 derived from the NCEP R-2. For SKT-T ${ }_{500}$ the values over land are not shown.

polar lows are described. Only those anomalies are discussed which are significant on the $99 \%$ level.

\subsubsection{Western Polar Lows}

[20] For the western polar lows the evolution of the polar low mean fields of sea level pressure, $\mathrm{GPH}_{500}$ and $\mathrm{SKT}-\mathrm{T}_{500}$ starting from $42 \mathrm{~h}$ prior to and ending $42 \mathrm{~h}$ after the key date are given in Animations 1 (top left) to 3 (top left). ${ }^{1}$ The corresponding anomaly patterns are shown in Figures 2 (top left) to 4 (top left) and Animations 4 (top left) to 6 (top left).

[21] A synoptic-scale surface ML is situated over the Norwegian Sea near the west coast of Norway. Western polar lows are located to the west of this ML in a northerly to northeasterly MF. Some of the observed polar lows also evolve near the center of the ML. The lowest pressure values of $993 \mathrm{hPa}$ are reached up to $30 \mathrm{~h}$ prior to the key date. The ML over the Norwegian Sea is up to $12 \mathrm{hPa}$ below the 2-year complementary mean at this time. A strong pressure gradient to the west of the synoptic-scale ML and hence strong mean northerly winds exist at key date. A dipole is visible in the anomaly patterns with an anomalous ridge over Greenland reaching into the Irminger Sea and an anomalous low over the Norwegian Sea. The synoptic-scale ML and the dipole decline during the decaying phase and the MF changes into a more easterly direction.

[22] A cold MT of the circumpolar vortex with minimum temperature and pressure values down to $233 \mathrm{~K}$ and 5120 geopotential meters (gpm) moves from the Fram Strait into the genesis region of the polar lows. This is connected with the development of a $\mathrm{GPH}_{500}$ anomaly reaching values of up to $240 \mathrm{gpm}$ below normal over the Norwegian Sea. In consistency with the results described above, polar low mean fields of IPV $_{315}$ derived from the NCEP R-1 (not shown) reveal a strong positive anomaly of IPV $_{315}$ over the genesis area of western polar lows. This is also the case for the other polar types which will be described below. During the decaying phase of western polar lows, the cold MT of the polar low mean field moves northeastward toward Spitzbergen, while the corresponding negative anomaly moves southeastward. The upper level MT and the surface ML are uncoupled during the early stages of polar low development.

[23] A large mean SKT-T ${ }_{500}$ difference of up to $42.5 \mathrm{~K}$, which is $9 \mathrm{~K}$ larger than normal, develops over the genesis region of western polar lows associated with the outbreak of upper level cold air over relatively warm water.

\subsubsection{Eastern Polar Lows}

[24] Animations 1 (bottom left) to 3 (bottom left) show the evolution of the polar low mean fields for eastern polar lows. The corresponding anomaly patterns are shown in Figures 2 (bottom left) to 4 (bottom left) and Animations 4 (bottom left) to 6 (bottom left). A synoptic-scale ML with a minimum pressure of $993 \mathrm{hPa}$ at key date is situated over the Barents Sea near Novaya Zemlya. Again, strong mean pressure gradients to the west of the synoptic-scale ML and hence strong mean winds exist at key date. An outstanding pattern is the pronounced dipole visible in the anomaly maps with positive values of up to $13.5 \mathrm{hPa}$ over Iceland and negative values of up to $15 \mathrm{hPa}$ over the Barents Sea. This dipole intensifies during the developing phase and weakens during the decaying phase. A northeasterly MF prevails during the development of the polar lows changing to a more easterly direction during the decaying phase.

[25] A cold upper level ML develops over the Barents Sea with minimum $\mathrm{GPH}_{500}$ and $\mathrm{T}_{500}$ values of $5090 \mathrm{gpm}$ and $233 \mathrm{~K}$, respectively. The related $\mathrm{GPH}_{500}$ anomaly

\footnotetext{
${ }^{1}$ Animations are available in the HTML.
} 

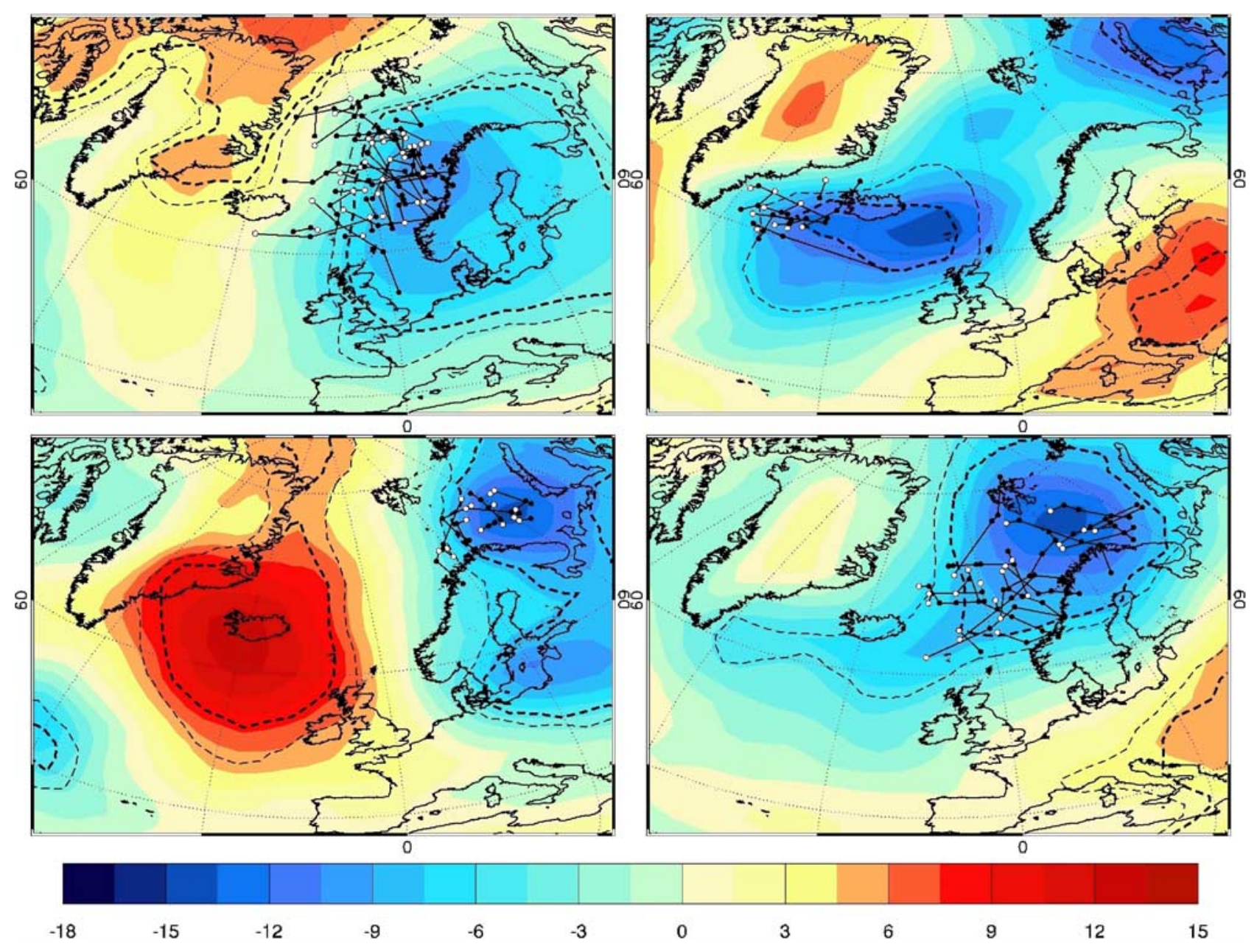

Figure 2. Anomalies of sea level pressure (hPa) at key date derived from the NCEP R-2 for (top left) western polar lows; (bottom left) eastern polar lows; (top right) Greenland lee polar lows; and (bottom right) storm track polar lows. The tracks of the polar lows are also given. The genesis regions of the polar lows are presented by the white circles. The thick dashed lines and the thin dashed lines represent the $99 \%$ and the $95 \%$ significance levels, respectively. The evolution of anomaly fields starting from $42 \mathrm{~h}$ prior to and ending $42 \mathrm{~h}$ after the key date are given in Animation 4.

reaches values of up to 240 below normal. It moves northward during the decaying phase toward the islands of Franz-Joseph Land.

[26] On average, a SKT-T ${ }_{500}$ difference of the same order of magnitude as for the western polar lows is connected with eastern polar low genesis.

\subsubsection{Greenland Lee Polar Lows}

[27] The evolution of the polar low mean fields for the Greenland lee polar lows are shown in Animations 1 (top right) to 3 (top right). The corresponding anomaly patterns are given in Figures 2 (top right) to 4 (top right) and Animations 4 (top right) to 6 (top right). A synoptic-scale ML with minimum values of $991 \mathrm{hPa}$, which is $16.5 \mathrm{hPa}$ below normal, evolves to the east of South Greenland. The ML starts to move along the major storm track (see section 3) during the developing phase of the polar lows. At key date the polar lows are situated on the western flank of this ML in a northeasterly MF down the Greenland coast. Pronounced mean pressure gradients and hence high mean wind speeds occur at the polar low locations.
[28] A cold MT of the circumpolar vortex moves eastward from Greenland into the genesis region of the polar lows where it reaches minimum values of $5150 \mathrm{gpm}$ and $233 \mathrm{~K}$, respectively. At key date, the temperature anomaly with values up to $12 \mathrm{~K}$ below normal is situated over the Denmark Strait close to the East coast of Greenland. The $500 \mathrm{hPa}$ MT propagates northeastward along the Denmark Strait during the decaying phase of the polar lows.

[29] A strong mean SKT-T ${ }_{500}$ difference moves around Cape Farewell prior to the key date. This difference reaches values of up to $45 \mathrm{~K}$ which is $12 \mathrm{~K}$ above normal at the genesis regions of the polar lows and decays about half a day after the key date. A splitting of the MF occurs as the anomaly moves around Cape Farewell.

\subsubsection{Storm Track Polar Lows}

[30] The evolution of the polar low mean fields for the storm track polar lows are given in Animations 1 (bottom right) to 3 (bottom right). The corresponding anomaly patterns are shown in Figures 2 (bottom right) to 4 (bottom 

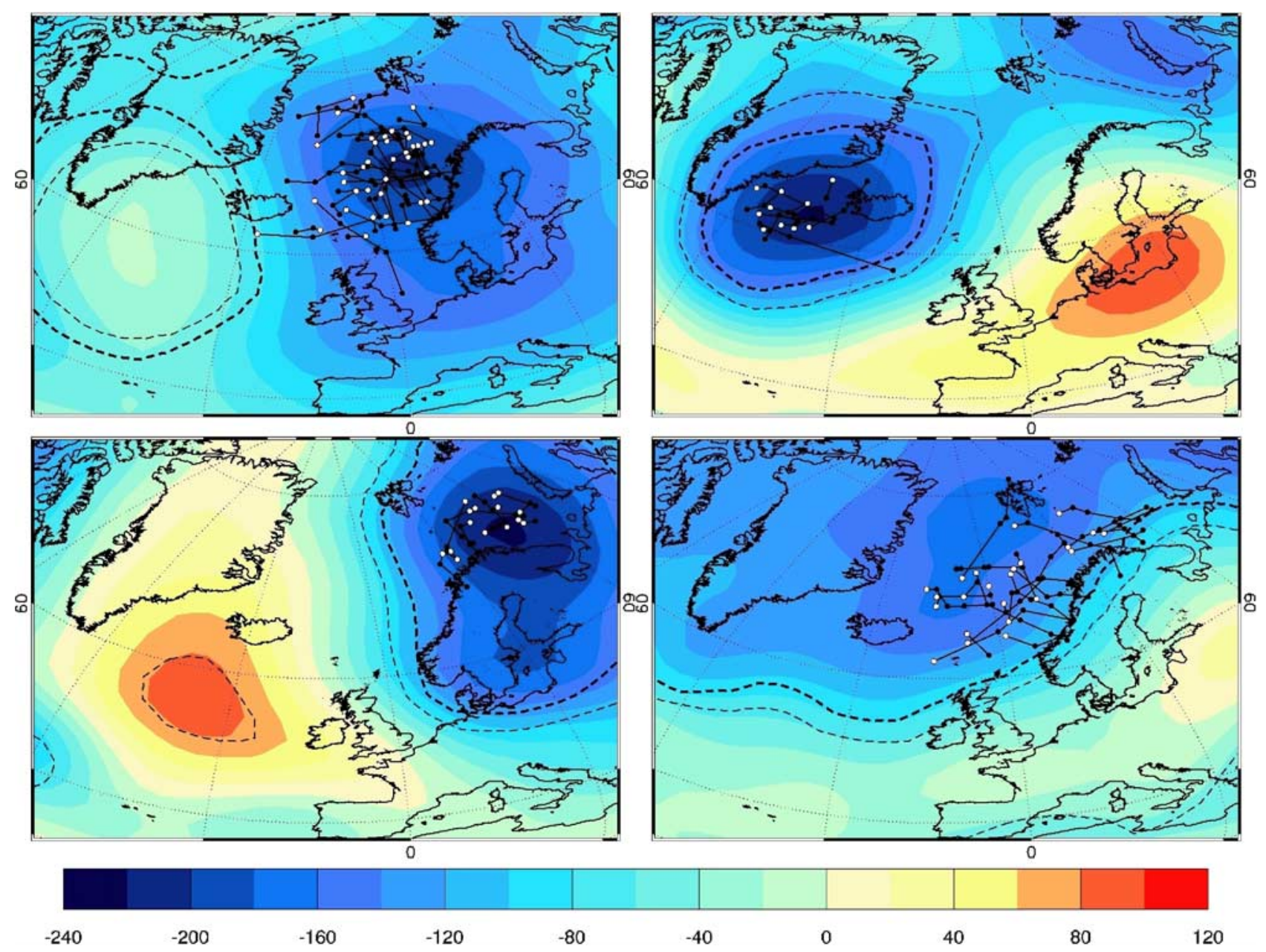

Figure 3. Same as Figure 2 but for the anomalies of $\mathrm{GPH}_{500}$ [gpm]. For the evolution of the fields, see Animation 5.

right) and Animations 4 (bottom right) to 6 . In these cases, a synoptic-scale ML moves along the major storm track (this feature is a direct consequence following from the definition of storm track polar lows described in section 3). At key date most of the polar lows are located at the trailing MT of this ML to the southwest of its center. Some of the polar lows are situated near the center. The pressure minimum reaches values of $991 \mathrm{hPa}$ which is $15 \mathrm{hPa}$ below normal at this time.

[31] An upper level cold MT of the circumpolar vortex moves to the northwest of the surface ML along the major storm track. On average, a SKT-T ${ }_{500}$ difference reaching values of up to $40 \mathrm{~K}$, which is $6 \mathrm{~K}$ above normal, develops over the genesis region of the polar lows.

\subsection{Genesis Values}

[32] The frequency distributions of minimum $\mathrm{GPH}_{500}$, minimum $\mathrm{T}_{500}$, maximum SKT- $\mathrm{T}_{500}$ and maximum IPV $\mathrm{P}_{315}$ derived at key date of every single polar low over its genesis region are presented in Figure 5. $\mathrm{GPH}_{500}$ values of $5030 \mathrm{gpm}$ and $\mathrm{T}_{500}$ values of $233 \mathrm{~K}$ are most often reached at the key date. Maximum IPV 315 values around 7 PVU are associated with upper level disturbances. For maximum SKT-T ${ }_{500}$ a value of $48 \mathrm{~K}$ is the most frequent. Only few polar lows reach larger values. This is in good agreement with Noer and Ovhed [2003], who found that a SKT-T ${ }_{500}$ difference of $45 \mathrm{~K}$ is associated with the development of polar lows near Norway. The values of the present study range from $32 \mathrm{~K}$ to $56 \mathrm{~K}$.

\section{Discussion}

[33] The findings described above show that common factors for all polar low types are pronounced upper level cold MTs or MLs and large differences between the SST and upper level temperature indicating strong vertical instability. The former is in agreement with several studies [e.g., Harrold and Browning, 1969; Businger and Reed, 1989; Noer and Ovhed, 2003] according to which an important factor for triggering polar low events is the approach of an upper level potential vorticity anomaly, i.e., a cold upper level low or trough. On average, polar lows develop in northerly cold flows to the west of large-scale lows. However, there are also specific differences between the circulation patterns associated with the different polar low types. These, as well as the relation to previous studies, will be discussed in the following. Schematic charts showing typical large scale circulation patterns associated with each 

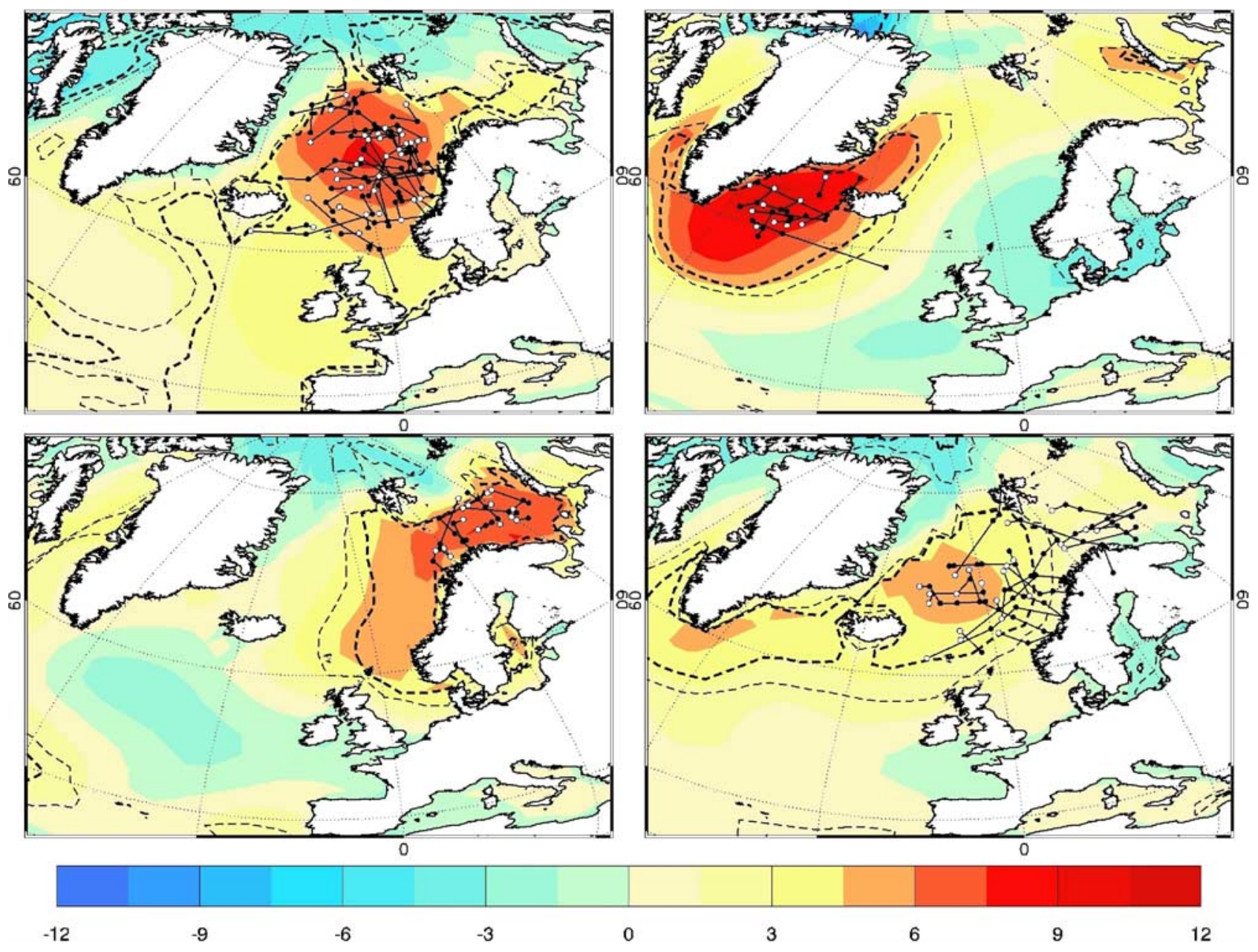

Figure 4. Same as Figure 2 but for the anomalies of SKT-T $500[\mathrm{~K}]$. The values over land are not shown. For the evolution of the fields, see Animation 6.

polar low type at key date as derived from the polar low mean fields and anomaly maps are given in Figure 6 and are summarized in Table 1. However, it should be kept in mind that it is beyond the scope of the present study to investigate the atmospheric conditions on the scale of the polar lows.

\subsection{Western Polar Lows}

[34] The typical large-scale circulation during western polar low events is given in Figure 6 (top left). The northeasterly surface MF caused by the synoptic-scale ML over the Norwegian Sea is directed almost parallel to the ice edge, assumed that the mean ice edge position is located near the $-1.8^{\circ} \mathrm{C}$ mean skin temperature contour. These estimated ice edge positions agree well with the ones given by Divine and Dick [2006], although the southward extent up to the southern tip of Greenland is probably overestimated. According to Businger and Reed [1989] a surface flow that is directed parallel to the ice edge favors the occurrence of boundary layer fronts separating relatively warm air over the open ocean from relatively cold air above sea ice or ice covered surfaces. These "Arctic fronts" which constitute regions of strong low-level baroclinicity, are frequently associated with synoptic activity in winter and often produce strong winds in the Arctic [Grønås and Skeie,
1999]. However, the applied reanalysis data set does not resolve these baroclinic zones sufficiently.

[35] An instability mechanism that has been regarded in previous studies as important for polar low formation is reverse shear baroclinicity [e.g., Duncan, 1978; Kolstad, 2006]. While most large, baroclinic waves develop when the surface wind, the thermal wind and the progression of the systems are in the same direction, reverse shear polar lows form when the surface and thermal wind are in opposite directions [Rasmussen and Turner, 2003]. According to Blechschmidt [2008] approximately $22 \%$ of the polar low events of the present study fulfill mostly similar largescale criteria for reverse shear as those defined by Kolstad [2006]. Reverse shear cases are present for all polar low types, though only one Greenland lee polar low case fulfills the criteria.

[36] The surface pressure anomaly maps resemble a blocking situation which favors the outbreak of cold air over the Norwegian Sea. The sea level pattern shows similarities to the one derived by Businger [1985], who found a mean ridge over Greenland and a ML with a center close to the north Norwegian coast. There are significant differences to the patterns by Ese et al. [1988], who did not find a mean ridge over Greenland for polar lows of his 
(a)

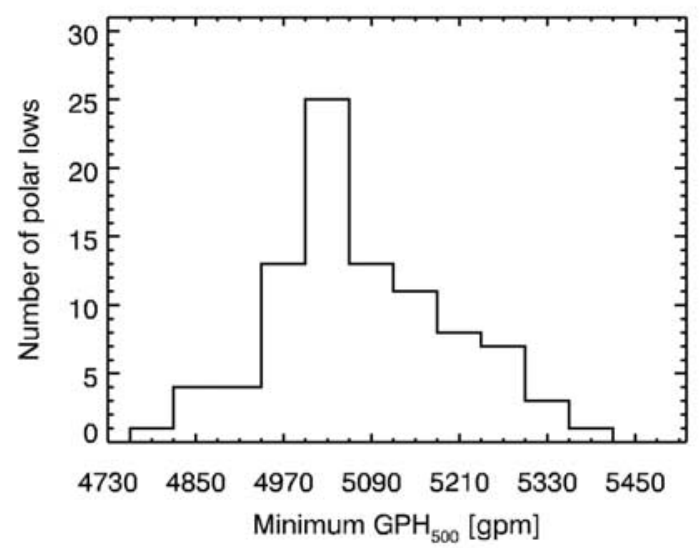

(b)

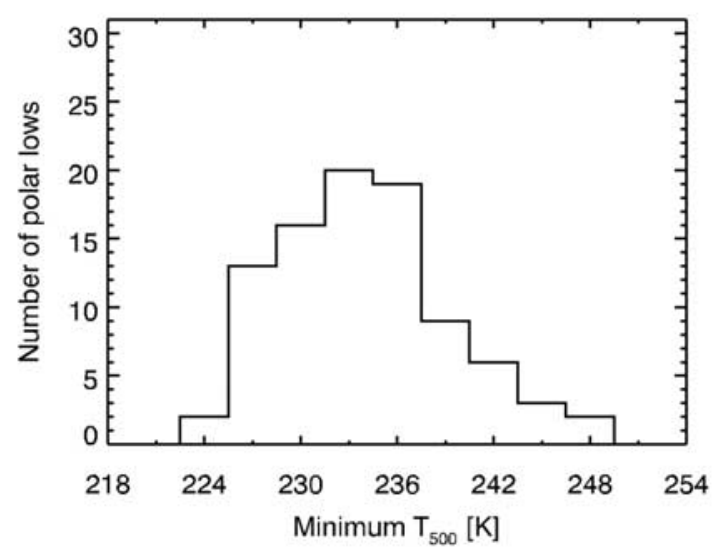

(c)

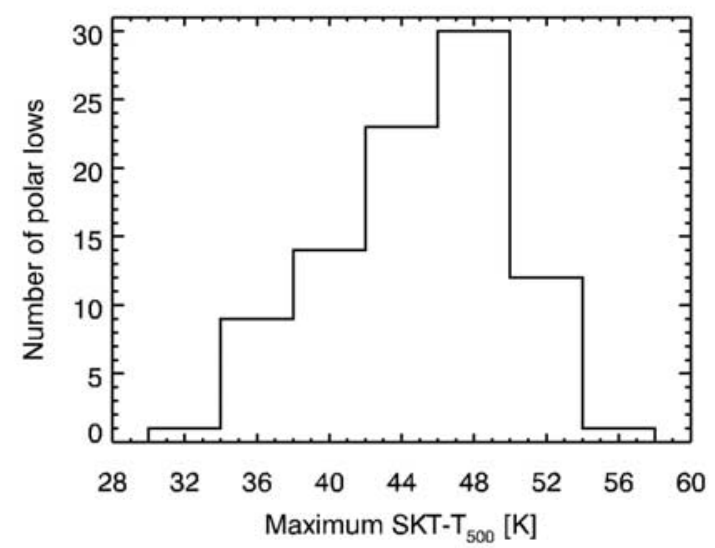

(d)

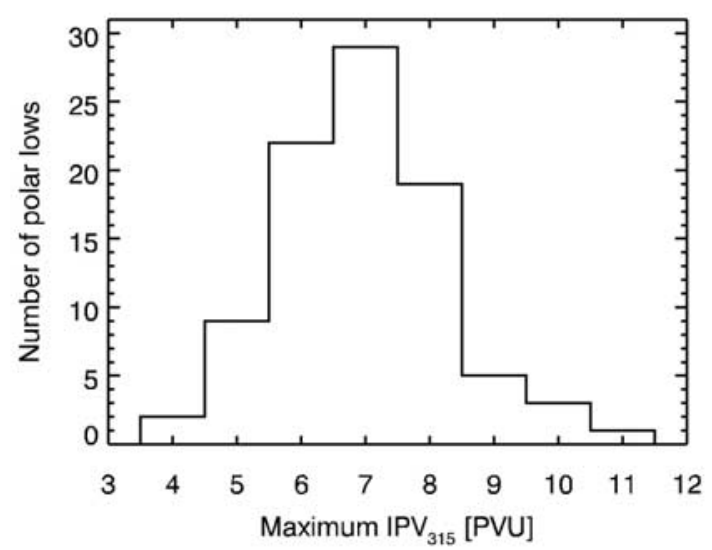

Figure 5. Frequency distributions of (a) minimum $\mathrm{GPH}_{500}$, (b) minimum $\mathrm{T}_{500}$, (c) maximum $\mathrm{SKT}-\mathrm{T}_{500}$ derived from NCEP R-2 and (d) maximum IPV 315 derived from NCEP R-1 for all observed polar lows at key date.

western group. Moreover, the outstanding positive anomaly of the Azores High in the sea level and upper level charts is not confirmed by the present study. The differences described above may be due to different polar low data sets, reanalysis data sets and classification procedures. An example for the latter is that Ese et al. [1988] did not exclude polar lows which develop in connection to synoptic-scale lows moving along the major storm track, which also develop in the region of their western and eastern polar low type. Moreover, the statistical analyses by Businger [1985] and Ese et al. [1988] mainly bases on polar low cases which gave wind force near or above gale at Norwegian meteorological stations or at weather ships near the Norwegian coast. The detection procedure is described in more detail by Wilhelmsen [1985]. The spatial distribution of the underlying polar low data set used by Businger [1985] and Ese et al. [1988] is most likely influenced by the available in situ observations. This may be another explanation for the difference between the patterns found by Businger [1985] and Ese et al. [1988] and those of the present study. The differences to polar lows of the eastern polar low type, which will be described below, may also be due to the reasons given above.
[37] The identified anomaly patterns of sea level pressure show similarities to those found by Kolstad et al. [2008] for their GIN Sea region, although they found a positive sea level pressure anomaly with a center situated to the southeast of Greenland. In the present study there is only a slight westward tilt with height between the negative sea level pressure anomaly over the Norwegian Sea and the corresponding negative height anomaly at upper levels (see Figures 2, top left, and 3, top left). On average, the atmosphere is weakly baroclinic on the synoptic scale during western polar low events. This agrees with Kolstad et al. [2008], who also found a baroclinic stratification.

[38] Rasmussen and Turner [2003] pointed out that as an upper level positive potential vorticity anomaly moves from over ice fields or snow covered land out across the relatively warm ocean, the tropospheric static stability may become very low, allowing efficient interaction between the upper disturbance and low-level features such as arctic fronts. That mobile upper level disturbances are indeed involved in a large portion of western polar low developments is suggested by the polar low mean fields of this polar low type. These show the approach of an upper level cold MT over the Norwegian Sea. 

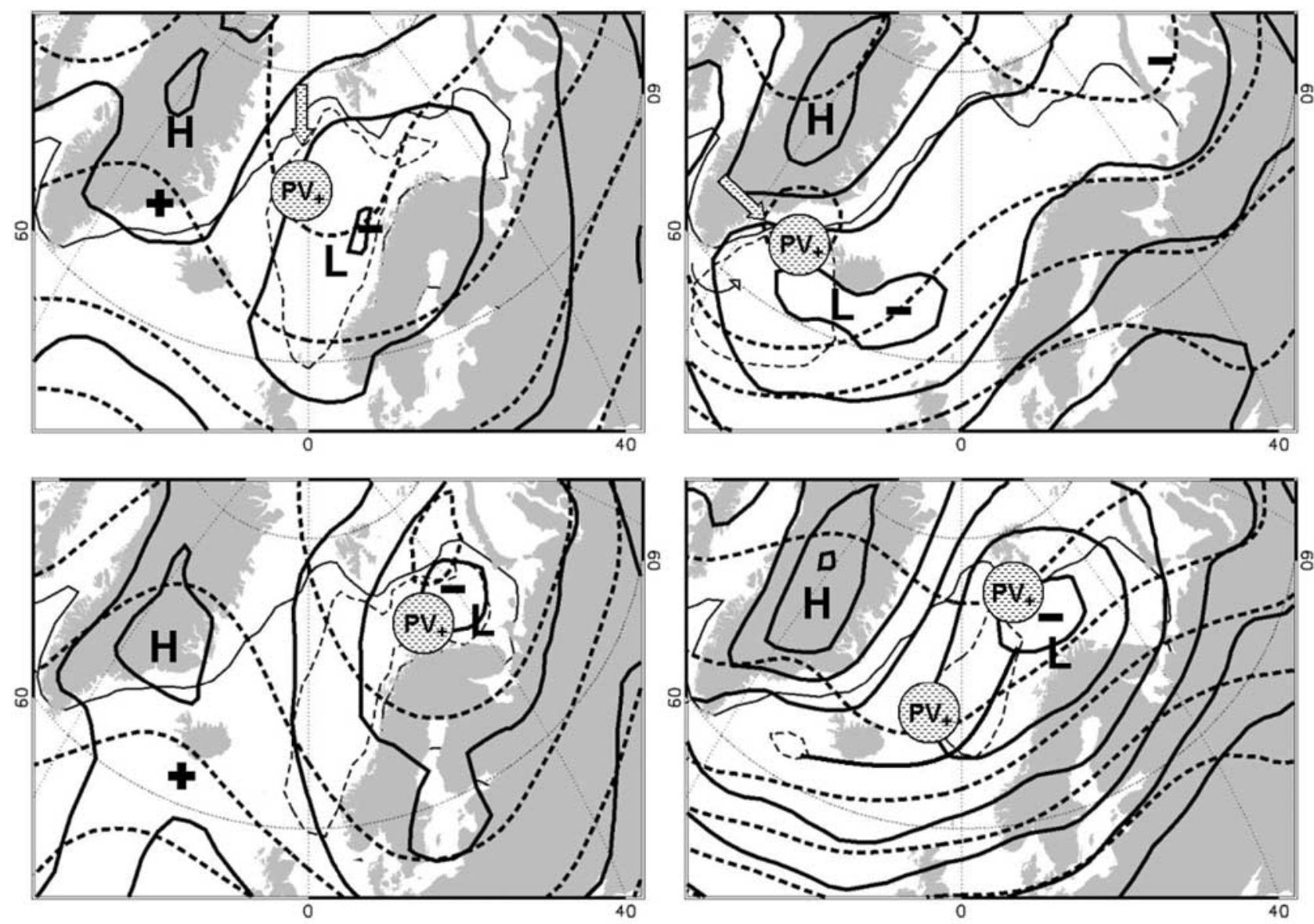

Figure 6. Schematic charts showing typical large-scale circulation patterns during key dates for (top left) western polar lows, (bottom left) eastern polar lows, (top right) Greenland lee polar lows, and (bottom right) storm track polar lows. Thick lines represent mean sea level pressure, thin lines show mean skin temperature of $-1.8^{\circ} \mathrm{C}$, thick dashed lines correspond to mean $\mathrm{GPH}_{500}$, and thin dashed lines to mean SKT-T ${ }_{500}=38 \mathrm{~K}$. The solid pluses and minuses mark the locations of strongest positive and negative sea level pressure anomalies. The hatched block arrows indicate the movement of upper level cold troughs. The thin arrow in Figure 6 (top right) indicates the movement of a large SKT-T 500 difference around Cape Farewell. The thick black line in Figure 6 (bottom right) denotes a low-level trailing trough. $\mathrm{PV}_{+}$marks the locations of strongest upper level positive potential vorticity disturbances.

\subsection{Eastern Polar Lows}

[39] The typical large-scale circulation during eastern polar low events is given in Figure 6 (bottom left). Eastern polar low events are associated with a strong blocking situation in which a high-pressure anomaly over Iceland and a low-pressure anomaly to the west of Novaya Zemlya favor the outbreak of cold air over the Barents Sea. Compared to the western polar low type, the dipoles are centered more eastward.

Table 1. Summary of Large-Scale Circulation Patterns Associated With Different Polar Low Types at Key Date

\begin{tabular}{|c|c|c|c|c|}
\hline Type & Sea Level Pressure & $\begin{array}{l}\text { Direction of Surface } \\
\text { Flow Relative to } \\
\text { Ice Edge }\end{array}$ & Upper Level Flow $^{\mathrm{a}}$ & Stratification \\
\hline West & $\begin{array}{l}\text { Ridge over Greenland, } \\
\text { low over Norwegian Sea }\end{array}$ & Parallel & $\begin{array}{l}\text { Cold trough moving southward } \\
\text { from Fram Strait associated with } \mathrm{PV}_{+}\end{array}$ & weakly baroclinic \\
\hline East & $\begin{array}{l}\text { Weak Icelandic Low, } \\
\text { low over Barents Sea }\end{array}$ & $\begin{array}{l}\text { Across } \\
\text { (from the ice) }\end{array}$ & Cold low over Barents Sea & weakly baroclinic \\
\hline Greenland lee & Low near Iceland & Parallel & $\begin{array}{l}\text { Cold trough passing Greenland } \\
\text { plateau associated with } \mathrm{PV}_{+}\end{array}$ & baroclinic \\
\hline Storm track & $\begin{array}{l}\text { Low moving along storm track, } \\
\text { trailing trough associated with } \\
\text { high values of low level vorticity }\end{array}$ & Parallel & Cold trough associated with storm track low & baroclinic \\
\hline
\end{tabular}

${ }^{\mathrm{a}} \mathrm{PV}+$ denotes an upper level positive potential vorticity disturbance. 
[40] There are some similarities to the patterns of the eastern polar low type described by Ese et al. [1988]. The location of the sea level MLs mostly agree. However, Ese et al. [1988] found a weaker mean ridge over Greenland and no strong low-pressure anomaly over Iceland. Moreover, the centers of the dipole identified by Kolstad et al. [2008] for their Barents Sea region and those of the present study broadly agree. As for western polar lows, the stratification of the atmosphere is, on average, weakly baroclinic on the synoptic scale since there is only a slight westward tilt with height between the negative anomalies in sea level pressure and $\mathrm{GPH}_{500}$ over the Barents Sea (see Figures 2, bottom left, to 3 , bottom left).

[41] Several studies [e.g., Shapiro et al., 1989; Grønås and Skeie, 1999] have shown that large amounts of sensible and latent heat can be transferred from the ocean to the atmosphere during outbreaks of cold air over a relatively warm ocean. These upward heat fluxes favor the development of polar lows [e.g., Emanuel and Rotunno, 1989; Claud et al., 2004]. The large-scale patterns for eastern polar lows suggest that this mechanism also contributes to the genesis of a large portion of eastern polar lows, since the surface MF is directed across the ice edge.

\subsection{Greenland Lee Polar Lows}

[42] The typical large-scale circulation during Greenland lee polar low events is given in Figure 6 (top right). A much stronger westward tilt with height is indicated by the sea level anomaly pattern and the anomaly pattern of $\mathrm{GPH}_{500}$ compared to the western and eastern polar low types (see Figures 2, top right, to 3, top right). On average, Greenland lee polar lows form in a baroclinic large-scale environment. The large-scale patterns indicate that the orography of Greenland has an impact on the development of a large portion of Greenland lee polar lows as will be described below. In the present study the largest $\mathrm{SKT} \mathrm{T}_{500}$ anomalies occur during Greenland lee polar low events compared to the other polar low types.

[43] Especially during the developing phase of the polar lows, the upper level MF is directed across the Greenland plateau. The polar lows reach their mature stage when the upper level cold MT, that originates from the Greenland plateau, enters their genesis region. This agrees well with Rasmussen and Turner [2003], who noted that polar lows near South Greenland form in a synoptic-scale westerly or northwesterly flow as the air is forced to flow around or over the southernmost part of the Greenland ice cap. Since the cold upper level MT is situated close to Angmagssalik/ Tasiilaq at key date, polar low development as described by Klein and Heinemann [2002] is possible. They found that the downslope flow from the Greenland ice sheet in the Angmagssalik area can trigger the development of shortlived mesocyclones close to the east coast of Greenland due to vortex stretching and the enhancement of low-level baroclinicty. The large-scale surface MF shows similarities to so-called "barrier flow events" over the Denmark Strait. These occur when the synoptic-scale flow forces cold air toward the east coast of Greenland, resulting in the development of a pressure gradient perpendicular to it [Moore and Renfrew, 2005].

\subsection{Storm Track Polar Lows}

[44] The typical large-scale circulation associated with storm track polar lows is given in Figure 6 (bottom right). On average, polar lows form in a northerly flow near or at the trailing trough of a synoptic-scale low associated with the major storm track in a baroclinic large-scale environment. At key date, the upper level cold MT associated with the synoptic-scale ML is located above the trailing MT at the ground. The mean SKT-T ${ }_{500}$ difference reaches much lower values for storm track polar lows compared to the other polar low types. This indicates that on average not as much static instability is present during the development of storm track polar lows.

[45] According to Rasmussen and Turner [2003] upper air charts show that polar lows forming within synopticscale surface troughs are generally triggered by upper level cold troughs. The surface trough is a region in which high vorticity values favor the development of mesoscale surface lows. The results described above suggest that these two mechanisms contribute to the development of many storm track polar lows.

\section{Summary and Concluding Remarks}

[46] The large-scale atmospheric circulation during polar low events over the Nordic seas has been investigated on the basis of a recently compiled data set that was derived from satellite observations. This is to our knowledge the first statistical analysis of large-scale atmospheric conditions during polar low events over the Nordic seas consistent with the definition of polar lows by Rasmussen and Turner [2003]. The evaluated polar low types show distinct, characteristic large-scale circulation patterns of sea level pressure, of upper level geopotential height, and of the difference between the skin temperature of the ocean and upper level temperature. This supports previous studies which used variables like $\mathrm{GPH}_{500}, \mathrm{~T}_{500}$ and $\mathrm{SKT}-\mathrm{T}_{500}$ to detect polar lows or favorable conditions for polar low development [e.g., Claud et al., 2007; Zahn and von Storch, 2008]. Eastern polar lows are found to be associated with a strong blocking situation caused by anomalously high pressure over Iceland and a synoptic-scale low-pressure anomaly over the Barents Sea. A weaker blocking situation with an anomalous ridge over Greenland reaching into the Irminger Sea and a low-pressure anomaly over the Norwegian Sea favors the development of western polar lows. The locations of upper level low-pressure anomalies relative to the locations of the related anomalies at the sea level show that western and eastern polar lows form, on average, in a much less baroclinic large-scale environment than Greenland lee and storm track polar lows. Typical values for polar low genesis are a $\mathrm{GPH}_{500}$ disturbance of 5030 gpm and a SKT-T $_{500}$ difference of $48 \mathrm{~K}$. The upper level disturbances most often occur in the form of cold troughs or lows of the circumpolar vortex.

[47] Acknowledgments. The research was funded by the Ph.D. program of HGF-VI EXTROP. Thanks to the people behind NOAA/ OAR/ESRL PSD and the CISL Research Data Archive for providing NCEP reanalysis data through their Web sites. We also thank Jenny Glashoff for her help with the data analysis. 


\section{References}

Andersson, A., S. Bakan, K. Fennig, H. Grassl, and C. P. Klepp (2007), Hamburg Ocean Atmosphere Parameters and fluxes from satellite dataHOAPS-3 - twice daily composite, World Data Cent. for Clim. doi:10.1594/WDCC/HOAPS3 DAILY. (Available at http://cera-www. dkrz.de/WDCC/ui/Compact.jsp?acronym=HOAPS3 DAILY)

Blechschmidt, A.-M. (2008), A 2-year climatology of polar low events over the Nordic seas from satellite remote sensing, Geophys. Res. Lett., 35 L09815, doi:10.1029/2008GL033706.

Bracegirdle, T. J., and S. L. Gray (2008), An objective climatology of the dynamical forcing of polar lows in the Nordic seas, Int. J. Climatol., 28 , $1903-1919$, doi:10.1002/joc. 1686.

Businger, S. (1985), The synoptic climatology of polar low outbreaks, Tellus, Ser. A, 37, 419-432.

Businger, S., and R. J. Reed (1989), Polar lows, in Polar and Arctic Lows, edited by P. F. Twitchell, E. A. Rasmussen, and K. L. Davidson, pp. 3 45, A. Deepak, Hampton, Va.

Claud, C., G. Heinemann, E. Raustein, and L. McMurdie (2004), Polar low le Cygne: Satellite observations and numerical simulations, $Q . J . R$ Meteorol. Soc., 130, 1075-1102.

Claud, C., B. Duchiron, and P. Terray (2007), Associations between largescale atmospheric circulation and polar low developments over the North Atlantic during winter, J. Geophys. Res., 112, D12101, doi:10.1029/ 2006JD008251.

Condron, A., G. R. Bigg, and I. A. Renfrew (2006), Polar mesoscale cyclones in the Northeast Atlantic: Comparing climatologies from ERA-40 and satellite imagery, Mon. Weather Rev., 134, 1518-1533.

Divine, D. V., and C. Dick (2006), Historical variability of sea ice edge position in the Nordic seas, J. Geophys. Res., 111, C01001, doi:10.1029/ 2004JC002851.

Duncan, C. N. (1978), Baroclinic instability in a reversed shear flow, Meteorol. Mag., 107, 17-23.

Emanuel, K. A., and R. Rotunno (1989), Polar lows as arctic hurricanes, Tellus, Ser. A, 41, 1-17.

Ese, T., I. Kanestrom, and K. Pedersen (1988), Climatology of polar lows over the Norwegian and Barents seas, Tellus, Ser. A, 40, 248-255.

Grønås, S., and N. G. Kvamstø (1995), Numerical simulations of the synoptic conditions and development of Arctic outbreak polar lows, Tellus, Ser. A, 47, 797-814.

Grønås, S., and P. Skeie (1999), A case study of strong winds at an Arctic front, Tellus, Ser. A, 51, 865-879.

Harrold, T. W., and K. A. Browning (1969), The polar low as a baroclinic disturbance, O. J. R. Meteorol. Soc., 95, 710-723.

Kanamitsu, M., W. Ebisuzaki, J. Woollen, S.-K. Yang, J. J. Hnilo, M. Fiorino, and G. L. Potter (2002), NCEP-DOE AMIP-II Reanalysis (R-2), Bull. Am. Meteorol. Soc., 83, 1631-1643, doi:10.1175/BAMS-83-11-1631.

Klein, T., and G. Heinemann (2002), Interaction of katabatic winds and mesocyclones near the eastern coast of Greenland, Meteorol. Appl., 9, 407-422.

Kolstad, E. W. (2006), A new climatology of favourable conditions for reverse-shear polar lows, Tellus, Ser. A, 58, 344-354.
Kolstad, E. W., T. J. Bracegirdle, and I. A. Seierstad (2008), Marine cold-air outbreaks in the North Atlantic: Temporal distribution and associations with large-scale atmospheric circulation, Clim. Dyn., doi:10.1007/ s00382-008-0431-5.

Mann, H. B., and D. R. Whitney (1947), On a test of whether one of two random variables is stochastically larger than the other, Ann. Math. Stat. $18,50-60$.

Mansfield, D. A. (1974), Polar lows. The development of baroclinic disturbances in cold air outbreaks, Q. J. R. Meteorol. Soc., 100, 541-554.

Moore, G. W. K., and I. A. Renfrew (2005), Tip jets and barrier winds: A QuikSCAT climatology of high wind speed events around Greenland, J. Clim., 18, 3713-3725

Noer, G., and M. Ovhed (2003), Forecasting of polar lows in the Norwegian and the Barents Sea, paper presented at 9th Meeting of the EGS Polar Lows Working Group, Cambridge, U. K.

Rasmussen, E. A. (1979), The polar low as an extratropical CISK disturbance, Q. J. R. Meteorol. Soc., 105, 531-549.

Rasmussen, E. A. (1983), A review of meso-scale disturbances in cold air masses, in Mesoscale Meteorology-Theories, Observations and Models, edited by D. K. Lilly and T. Gal-Chen, pp. 247-283, D. Reidel, Boston, Mass.

Rasmussen, E. A., and J. Turner (2003), Polar Lows: Mesoscale Weather Systems in the Polar Regions, Cambridge Univ. Press, Cambridge, U. K.

Reed, R. J. (1979), Cyclogenesis in polar airstreams, Mon. Weather Rev., 107, 38-52.

Reed, R. J., and C. N. Duncan (1987), Baroclinic instability as a mechanism for the serial development of polar lows: A case study, Tellus, Ser. A, 39, $376-384$.

Sardie, J. M., and T. T. Warner (1985), A numerical study of the development mechanisms of polar lows, Tellus, Ser. A, 37, 460-477.

Shapiro, M. A., T. Hampel, and L. S. Fedor (1989), Research aircraft observations of an arctic front over the Barents Sea, in Polar and Arctic Lows, edited by P. F. Twitchell, E. A. Rasmussen, and K. L. Davidson, pp. 3-45, A. Deepak, Hampton, Va.

Whittaker, L. M., and L. H. Horn (1984), Northern Hemisphere extratropical cyclone activity for four mid-season months, J. Climatol., 4, 297310

Wilhelmsen, K. (1985), Climatological study of gale-producing polar lows near Norway, Tellus, Ser. A, 37, 451-459.

Zahn, M., and H. von Storch (2008), A long-term climatology of North Atlantic polar lows, Geophys. Res. Lett., 35, L22702, doi:10.1029/ 2008GL035769.

Zahn, M., H. von Storch, and S. Bakan (2008), Climate mode simulation of North Atlantic polar lows in a limited area model, Tellus, Ser. A, 60, 620631 .

S. Bakan, Max Planck Institute for Meteorology, Bundesstrasse 53 , D-20146 Hamburg, Germany.

A.-M. Blechschmidt and H. Graß1, Meteorological Institute, University of Hamburg, Bundesstrasse 55, D-20146 Hamburg, Germany. (anne. blechschmidt@zmaw.de) 